\title{
Risk factors for surgical site infection in a teaching hospital: a prospective study of I, I 38 patients
}

\author{
This article was published in the following Dove Press journal: \\ Patient Preference and Adherence \\ 14 August 2015 \\ Number of times this article has been viewed
}

\author{
Keping Cheng \\ Jiawei Li \\ Qingfang Kong \\ Changxian Wang \\ Nanyuan Ye \\ Guohua Xia
}

Department of Infection Control, Zhongda Hospital, School of Medicine, Southeast University, Nanjing, Jiangsu Province, People's Republic of China

Correspondence: Keping Cheng Department of Infection Control, Zhongda Hospital, School of Medicine, Southeast University, Gulou district of Nanjing 210009, People's Republic of China

Tel +86258327 2069

Email lcxgh@I63.com
Background: The purpose of this study was to identify risk factors for surgical site infection (SSI) in a teaching hospital.

Methods: A prospective study was initiated to investigate risk factors for SSI at a universityaffiliated tertiary care center from July 2013 to December 2014. The chi-square test for categorical variables was used to determine the significance of association, whereas the multivariate logistic regression model was used to examine independent risk factors for SSI.

Results: A total of 1,138 patients met the inclusion criteria, in whom 36 cases of infection occurred during the hospitalization period and two cases occurred after discharge. Univariate analysis showed that SSI was associated with the type of operation, wound classification, volume of blood loss, blood transfusion, American Society of Anesthesiology score before surgery, risk index, duration of surgery, diabetes, cancer, gastrointestinal catheter, urinary catheter, postoperative drainage, and preprocedural white blood cell count. Multivariate analysis identified six independent parameters correlating with the occurrence of SSI: diabetes (odds ratio [OR] 6.400; 95\% confidence interval [CI] 2.582-15.866; $P=0.000$ ); cancer (OR 2.427; 95\% CI 1.028-5.732; $P=0.043$ ); preprocedural white blood cell count more than $10 \times 10^{9} / \mathrm{L}$ (OR 6.988; CI 3.165-15.425; $P=0.000$ ); wound classification (clean contaminated [OR: 7.893; CI: 2.244-27.762; $P=0.001$ ]; contaminated [OR: 7.031; CI: 1.652-29.922; $P=0.008$ ]; dirty [OR: 48.778; CI: 5.418-439.164; $P=0.001]$ ); operative duration more than 120 minutes (OR 4.289; CI 1.773-10.378; $P=0.001$ ); and postoperative drainage (OR 3.957; CI 1.422-11.008; $P=0.008$ ).

Conclusion: Our data suggest that all these risk factors could be regarded as potential indicators of SSI and that relevant preventive measures should be taken to reduce SSI and improve patient outcomes.

Keywords: wound classification, surgical site infection, nosocomial infection, risk factors

\section{Introduction}

The surgery department is a place with a high incidence of nosocomial infection, and accumulating evidence suggests advances have been made in infection control practices, ${ }^{1,2}$ including improved operating room ventilation, sterilization methods, barriers, surgical techniques, and availability of antimicrobial prophylaxis. However, surgical site infection (SSI) remains a substantial cause of morbidity, prolongs hospitalization, and increases death. SSI rates have been reported to range from less than $1 \%$ to more than $10 \%$, and $75 \%$ of SSI-associated deaths are directly attributable to SSI. ${ }^{3}$ The occurrence of SSI is not only a serious threat to the patient's health and life, but also imposes a substantial economic burden on the patient's family and society. ${ }^{4-6}$ Early diagnosis and treatment of infection is essential in the care of surgical patients. Thus, it is urgent that we identify the factors responsible for SSI and, if possible, corresponding measures should be taken to prevent the occurrence of nosocomial infection, alleviate patients' pain, speed their recovery, and reduce their medical expenses. 


\section{Subjects and methods}

This study was carried out prospectively at the Department of Infection Control, Zhongda Hospital, which has more than 2,600 beds and is affiliated to Southeast University. The study was approved by the ethics committee of Southeast University.

\section{Study population}

A total of 1,138 patients who had surgery at the teaching hospital affiliated to Southeast University from July 2013 to December 2014, were studied prospectively. Patients admitted to the hospital for more than 1 day were included, while outpatients and those who had surgery elsewhere before referral to our hospital were excluded.

\section{Survey method}

Based on patient information gathered from the computer network system and from ward rounds in the teaching hospital, system monitoring of SSI was filled in survey forms according to the software of Nosocomial Infection Monitoring Management System developed by Beijing Minke Medical Electronic Technology Research Institute. All patients were followed up from the time of admission until the time of discharge and 30 days postoperatively to inspect the incidence of SSI. ${ }^{7}$

\section{Diagnostic criteria}

Patients were evaluated for SSI according to the Nosocomial Infection Diagnostic Criteria published by China's Ministry of Health in $2001 .^{8}$

\section{Risk index calculation}

According to the Monitoring Standard of Nosocomial Infection requirements issued by the Ministry of Health, the risk index for each operation in this survey was calculated according to the accumulation points of three risk factors, ie, operative duration, surgical wound classification system, and American Society of Anesthesiology (ASA) score. In our daily work, the risk index for each operation was automatically generated by the Nosocomial Infection Monitoring Management System software using the aforementioned factors.

\section{Statistical analysis}

All of the data were checked and analyzed with Statistical Package for the Social Sciences version 19.0 software (SPSS Inc., Chicago, IL, USA). First, descriptive statistics, including count and percentage, were used to describe the demographic characteristics of the subjects. Univariate analysis for association between identified risk factors and SSI was performed using chi-square tests for discrete variables, and $P<0.05$ was accepted as statistically significant. When the $P$-value was less than 0.05 , multivariate logistic regression was performed using the stepwise forward method to identify those factors most significantly associated with risk of infection; the $P$-value for significance was set at 0.01 and the results are presented with an odds ratio (OR) and a $95 \%$ confidence interval (CI).

\section{Study limitation}

Either chlorhexidine bathing or normothermia could have contributed to the low prevalence of SSI.

\section{Results}

\section{Patient information}

Details on 1,138 patients who underwent breast, hernia, esophagus, stomach, appendix, colon, or rectal surgery at a university-affiliated tertiary care center were retrieved from an SSI database. The mean patient age was 54.62 (range 2-92) years; 542 were male and 596 were female.

\section{Incidence and cause of SSI}

Our analysis showed that 38 of the 1,138 patients suffered from SSI, giving an incidence of $3.34 \%$. Thirty-six of the SSI cases occurred during hospitalization and two occurred after discharge. The 38 cases comprised 30 superficial incisional infections, six deep incisional infections, and six, two organ/ space infections. Twenty bacterial strains were isolated from the infected surgical incision sites, including Escherichia coli, Staphylococcus aureus, and Pseudomonas aeruginosa.

\section{Univariate analysis}

The association between potential risk factors and SSI was performed using the chi-square test for discrete variables. Risk factors significantly associated with SSI were diabetes, cancer, wound classification, ASA scores before surgery, preprocedural white blood cell count (WBC), type of surgery, volume of blood loss, blood transfusion, operative duration, risk index, use of a gastrointestinal or urinary catheter, and postoperative drainage. In contrast, risk factors determined not to be significantly associated with SSI were sex, age, skin preparation, use of a trachea cannula, antibiotic prophylaxis, and type of anesthesia $(P>0.05$; Table 1$)$.

\section{Multivariate logistic regression analysis}

Based on the results of the chi-square test, six risk factors identified in univariate analysis were analyzed further by mul- 
Table I Analysis of patient factors related to surgical site infections using the chi-square test

\begin{tabular}{|c|c|c|}
\hline Risk factor (n) & $\begin{array}{l}\text { Infection cases } \\
\text { (incidence, \%) }\end{array}$ & $\begin{array}{l}\chi^{2} \\
\text { (P-value) }\end{array}$ \\
\hline \multicolumn{3}{|l|}{ Sex } \\
\hline Male (542) & $19(3.5)$ & 0.089 \\
\hline Female (596) & $19(3.2)$ & $(0.776)$ \\
\hline \multicolumn{3}{|l|}{ Age (years) } \\
\hline$<75$ (977) & $29(3.0)$ & 2.944 \\
\hline$\geq 75(161)$ & $9(5.6)$ & $(0.086)$ \\
\hline \multicolumn{3}{|l|}{ Pre-morbidity } \\
\hline \multicolumn{3}{|l|}{ Diabetes } \\
\hline Yes (77) & II (I4.3) & 30.660 \\
\hline No $(I, 06 I)$ & $27(2.5)$ & $(0.000)$ \\
\hline \multicolumn{3}{|l|}{ Cancer } \\
\hline Yes (119) & $10(8.4)$ & 10.559 \\
\hline No $(1,019)$ & $28(2.7)$ & $(0.001)$ \\
\hline \multicolumn{3}{|l|}{ Wound classification } \\
\hline Clean (639) & $3(0.5)$ & \\
\hline Clean contaminated (379) & $24(6.3)$ & 60.768 \\
\hline Contaminated $(I \mid 2)$ & $8(7.1)$ & $(0.000)$ \\
\hline Dirty (8) & $3(37.5)$ & \\
\hline \multicolumn{3}{|l|}{ ASA score before operation } \\
\hline Level I (387) & $3(0.8)$ & \multirow{5}{*}{$\begin{array}{l}33.411 \\
(0.000)\end{array}$} \\
\hline Level II (576) & $19(3.3)$ & \\
\hline Level III (I39) & $13(9.4)$ & \\
\hline Level IV (9) & $2(22.2)$ & \\
\hline Level V (27) & I (3.7) & \\
\hline \multicolumn{3}{|l|}{ Skin preparation } \\
\hline Yes $(423)$ & $13(3.1)$ & 0.147 \\
\hline No $(7 \mid 5)$ & $25(3.5)$ & $(0.70 I)$ \\
\hline \multicolumn{3}{|l|}{ Preprocedural WBC (×109/L) } \\
\hline$\leq 10(988)$ & $20(2.0)$ & 40.151 \\
\hline$>10(150)$ & $18(12.0)$ & $(0.000)$ \\
\hline \multicolumn{3}{|l|}{ Type of surgery } \\
\hline Selective (972) & $24(2.5)$ & 15.628 \\
\hline Emergency (166) & $14(8.4)$ & $(0.000)$ \\
\hline \multicolumn{3}{|l|}{ Type of anesthesia } \\
\hline General anesthesia $(8 \mid 2)$ & $32(3.9)$ & 4.225 \\
\hline Balanced anesthesia (48) & $2(4.2)$ & $(0.376)$ \\
\hline Epidural anesthesia (I3) & $0(0.0)$ & \\
\hline Local anesthesia (263) & $4(1.5)$ & \\
\hline Other (2) & $0(0.00)$ & \\
\hline \multicolumn{3}{|l|}{ Volume of blood loss (mL) } \\
\hline$<200$ (869) & $19(2.2)$ & \multirow{3}{*}{$\begin{array}{l}18.057 \\
(0.000)\end{array}$} \\
\hline $200-400(213)$ & $13(6.1)$ & \\
\hline$\geq 400$ (56) & $6(10.7)$ & \\
\hline \multicolumn{3}{|l|}{ Blood transfusion } \\
\hline Yes (56) & $6(10.7)$ & 9.925 \\
\hline No $(I, 082)$ & $32(3.0)$ & $(0.002)$ \\
\hline \multicolumn{3}{|l|}{ Risk index } \\
\hline $0(673)$ & $9(1.3)$ & \\
\hline I (377) & $22(5.8)$ & 22.001 \\
\hline $2(78)$ & $4(5.1)$ & $(<0.000)$ \\
\hline $3(10)$ & $3(30.0)$ & \\
\hline \multicolumn{3}{|l|}{ Operative duration (minutes) } \\
\hline$<120(553)$ & $8(1.4)$ & 11.937 \\
\hline$\geq 120(585)$ & $30(5.1)$ & $(0.00 I)$ \\
\hline
\end{tabular}

Table I (Continued)

\begin{tabular}{|c|c|c|}
\hline Risk factor (n) & $\begin{array}{l}\text { Infection cases } \\
\text { (incidence, \%) }\end{array}$ & $\begin{array}{l}\chi^{2} \\
\text { (P-value) }\end{array}$ \\
\hline \multicolumn{3}{|l|}{ Catheter } \\
\hline \multicolumn{3}{|c|}{ Gastrointestinal catheter } \\
\hline Yes (353) & $25(7.1)$ & 22.212 \\
\hline No $(785)$ & $13(1.7)$ & $(0.000)$ \\
\hline \multicolumn{3}{|l|}{ Urinary catheters } \\
\hline Yes $(42 \mathrm{I})$ & $23(2.1)$ & 9.339 \\
\hline No (7I7) & $15(5.5)$ & $(0.002)$ \\
\hline \multicolumn{3}{|l|}{ Trachea cannula } \\
\hline Yes (402) & $13(3.2)$ & 0.021 \\
\hline No $(736)$ & $25(3.4)$ & $(0.884)$ \\
\hline \multicolumn{3}{|c|}{ Postoperative drainage } \\
\hline Yes (539) & $33(6.1)$ & 24.576 \\
\hline No (599) & $5(0.8)$ & $(0.000)$ \\
\hline \multicolumn{3}{|c|}{ Antibiotic prophylaxis } \\
\hline Yes (944) & $28(3.0)$ & 2.388 \\
\hline No (194) & $10(5.2)$ & $(0.122)$ \\
\hline
\end{tabular}

Abbreviations: ASA, American Society of Anesthesiologists; WBC, white blood cell count.

tivariate logistic regression analysis using a forward conditional model (Table 2). This analysis identified six parameters as independent markers for occurrence of SSI: diabetes (OR 6.400; 95\% CI 2.582-15.866; $P=0.000$ ); cancer (OR 2.427; CI 1.028-5.732; $P=0.043)$; preprocedural WBC more than $10 \times 10^{9} / \mathrm{L}$ (OR 6.988; CI 3.165-15.425; $P=0.000$ ); wound classification (clean contaminated [OR: 7.893; CI: 2.244 27.762; $P=0.001$ ]; contaminated [OR: 7.031; CI: 1.652 29.922; $P=0.008$ ]; dirty [OR: 48.778; CI: 5.418-439.164; $P=0.001]$ ); operative duration more than 120 minutes (OR 4.289; CI 1.773-10.378; $P=0.001)$; and postoperative drainage (OR 3.957; CI 1.422-11.008; $P=0.008$ ).

\section{Discussion}

SSIs are the second most common type of adverse events occurring in hospitalized patients following surgery and are one of the most common surgical complications. ${ }^{9-12}$ SSI surveillance is integral to hospital infection control and quality improvement programs, with feedback of SSI rates being an important component of SSI reduction strategies. ${ }^{13}$ The incidence of SSI differs widely from hospital to hospital and from one geographic location to another. ${ }^{14}$ In the People's Republic of China, surgical site infections are still one of the leading causes of morbidity and mortality among patients undergoing major surgery. The incidence of SSI in various hospitals varies from $13.0 \%$ to $18.0 \%$, and accounts for $25.0 \%$ of all nosocomial infection, ${ }^{1}$ which is higher than in other countries. ${ }^{3}$ The incidence of SSI in our survey was $3.34 \%$, which is far lower than that of the national average. ${ }^{15}$ This finding is likely to be the result of 
Table 2 Analysis of risk factors for surgical site infection using a multivariate logistic regression model

\begin{tabular}{|c|c|c|c|c|c|c|c|}
\hline \multirow[t]{2}{*}{ Risk factor } & \multicolumn{6}{|c|}{ Variables in the equation } & \multirow[t]{2}{*}{ Reference } \\
\hline & $\beta$ & SE & Wald & $P$-value & OR & $95 \% \mathrm{Cl}$ & \\
\hline Diabetes & 1.856 & 0.463 & 16.059 & 0.000 & 6.400 & $2.582-15.866$ & No \\
\hline Cancer & 0.887 & 0.438 & 4.093 & 0.043 & 2.427 & $1.028-5.732$ & No \\
\hline \multicolumn{8}{|c|}{ Preprocedural WBC $\left(\times 10^{9} / \mathrm{L}\right)$} \\
\hline$>10$ & 1.944 & 0.404 & 23.157 & 0.000 & 6.988 & $3.165-15.425$ & $\leq 10$ \\
\hline \multicolumn{8}{|l|}{ Wound classification } \\
\hline Clean contaminated & 2.066 & 0.642 & 10.364 & 0.001 & 7.893 & $2.244-27.762$ & Clean \\
\hline Contaminated & 1.950 & 0.739 & 6.966 & 0.008 & 7.031 & $1.652-29.922$ & \\
\hline Dirty & 3.887 & 1.121 & 12.020 & 0.001 & 48.778 & $5.418-439.164$ & \\
\hline \multicolumn{8}{|l|}{ Operative duration } \\
\hline \multicolumn{8}{|l|}{ (minutes) } \\
\hline$\geq 120$ & 1.456 & 0.451 & 10.433 & 0.001 & 4.289 & $1.773-10.378$ & $<120$ \\
\hline Postoperative drainage & 1.375 & 0.522 & 6.942 & 0.008 & 3.957 & $1.422-11.008$ & No \\
\hline
\end{tabular}

Notes: $\beta$ indicates the partial regression coefficient, and $95 \% \mathrm{Cl}$ is credibility interval of $95 \%$ standard partial regression coefficient.

Abbreviations: $\mathrm{Cl}$, confidence interval; OR, odds ratio; SE, standard error; WBC, white blood cell count.

a multifactorial approach to improving patient safety and outcomes, especially the clinical real-time network monitoring performed since 2011. Moreover, the results of logistic regression analysis showed that SSI was related to type of operation, wound classification, volume of blood loss, blood transfusion, ASA score before operation, risk index, operative duration, diabetes, cancer, use of a gastrointestinal or urinary catheter, postoperative drainage, preprocedural WBC, suggesting that all patients having any type of operative procedure should be monitored for potential triggers of SSI in routine clinical practice.

The potential risk factors for SSI in surgical patients in our present study were assessed, and details were recorded preoperatively, intraoperatively, and postoperatively. Various patient risk factors were found to predict the incidence of SSI, in agreement with previously reported findings. ${ }^{16}$ In our present study, an association was found between the age of surgical patients and SSI, suggesting that patients aged over 75 years $(5.6 \%)$ were more likely to develop SSI than those under the age of 75 years (3.0\%). However, this association failed to reach statistical significance $(P>0.05)$. The lack of a significant association in this study may be due to the fact that elderly patients with chronic underlying disease often have decreased physiological defense mechanisms and poorer immune function. Therefore, elderly patients should undergo elective surgery when their bodies are in good condition.

The clinical relevance of these findings is that patients suffering from serious pre-existing disease, such as diabetes or cancer, are at high risk of developing SSI. In this study, there was a significant correlation between existing cancer and the likelihood of SSI. This is similar to the findings of other study of SSI. ${ }^{7}$ Further, published reports have demonstrated that patients with diabetes are more susceptible to wound infection because of impaired neutrophil chemotaxis and phagocytosis. ${ }^{17,18}$ The incidence of SSI in diabetic patients was higher, and there was a significant difference between the diabetic and non-diabetic groups in our survey. This is in accordance with the literature, which shows that patients suffering from pre-morbid diseases are at high risk of SSI. ${ }^{19}$ Moreover, the results of our multivariate logistic regression analysis showed that diabetes was an independent risk factor for SSI (OR 6.400; 95\% CI 2.582-15.866). As we know, the risk of SSI is very different for a patient who is having surgery to remove cancer when compared with a patient who is healthy and having knee replacement surgery. Thus, preexisting disease may be one of the possible risk factors of SSI, but it is important to consider the type of disease presented.

Despite improvements in operating room practices, instrument sterilization methods, surgical technique, and the best efforts of infection prevention strategies, SSI remains a major cause of hospital-acquired infections and rates are increasing globally even in hospitals with the most modern facilities and standard protocols for preoperative preparation. ${ }^{7}$ Thus, SSI is considered to be one of the most common and serious anesthetic and surgical complications. ${ }^{20}$ It is well known that intraoperative or postoperative variable factors for SSI may reflect surgical technique more than patient case-mix. Emergency operative procedures do not allow for the standard preoperative preparation normally done within a facility for a scheduled operation (eg, confirmation of stable vital signs, adequate antiseptic skin preparation, and decontamination of the colon in advance of colon surgery). As shown in Table 1, the incidence of SSI in emergency surgery cases was higher than in elective surgery cases ( $8.4 \%$ versus $2.5 \%$, respectively), 
which is in accordance with other studies. ${ }^{21,22}$ Patients with acute abdominal pain account for the majority of emergency surgeries, and are at high perioperative risk for SSI because of the infected operation, especially at the preoperative infection lesions. On the other hand, most of the emergency surgeries were carried out beyond normal duty working hours and inadequate preoperative preparation might be a possible explanation for the higher incidence of SSI. Therefore, it is of high importance to strengthen the management of emergency surgery.

The type of anesthesia used depends on the procedure being performed and the patient's health, age, and preferences. Several studies have reported an increased SSI rate in patients undergoing general anesthesia when compared with those undergoing regional anesthesia. ${ }^{23,24}$ However, there was no significant difference between them in our study. This finding has been proved by another study. ${ }^{15}$

Before each operative procedure, at least one incision (including for the laparoscopic approach) is made through the skin or mucous membrane, or reoperation via an incision that was left open. ${ }^{25}$ Surgical wound classification has long been established as an important predictor of postoperative SSI. ${ }^{26}$ The present survey showed that the incidence of SSI was higher in patients with a contaminated incision than in those with a clean or clean contaminated incision. The results of our multivariate logistic regression analysis further showed that wound classification was an independent risk factor for SSI, and the $95 \%$ CI for a dirty wound was much wider than the other ones of wound classification, but this may reflect the relatively small number of patients. We isolated 20 strains of bacteria, including E. coli, S. aureus, and P. aeruginosa, from infected surgical incision sites. Therefore, preventive measures should be strengthened for operations involving a contaminated incision, such as skin incision protection, minimizing contamination in the surgical field, and use of antibiotics. Reducing SSI while minimizing antibiotic resistance remains a challenge for many health care institutions. Use of perioperative antibiotics for incisions susceptible to infection did not seem to reduce the risk of SSI in our setting, as in other reports. ${ }^{27,28}$ The lack of statistical significance could be explained in part by the lack of a perioperative antibiotic policy regarding different procedures for those patients in our study. Further, use of surgical drains as well as arteriovenous catheters and tracheal cannulae has been reported to be associated with an increased risk of SSI, ${ }^{29,30}$ and multivariate analysis identified use of an arteriovenous catheter as a risk factor for SSI in our study. In contrast, tracheal cannulation was not associated with SSI. Thus, arteriovenous catheterization can alert surgeons to the increased risk of SSI, and nurses should be familiar with the monitoring and man- agement of surgical drains to reduce this risk. ${ }^{31}$ An operative duration of longer than 2 hours has previously been reported to be associated with SSI due to the increased duration of exposure to microorganisms in the operating theater, ${ }^{32,33}$ and appeared to be a risk factor for SSI in our univariate analysis. It has also been demonstrated elsewhere by multivariate regression that increasing operative duration is associated with a stepwise increase in SSI. ${ }^{1}$ Our multivariate logistic regression results further showed that operative duration was an independent risk factor for SSI, with an OR of 4.289 and a 95\% CI of 1.773-10.378. Therefore, SSI prevention strategies focusing on longer surgical duration are needed to improve the outcomes for patients.

The relationship between blood products and SSI has been a matter of debate for more than 2 decades. It has been established that the incidence of SSI increases with increasing volume of blood transfusion. ${ }^{34}$ In our study, the incidence of SSI in patients who received transfusions $(10.7 \%)$ was higher than in those who did not (3.0\%), suggesting that surgical patients who receive blood transfusion are more prone to SSI. Therefore, clinicians should not use blood transfusions unless absolutely necessary.

The ASA score evaluates the basal status of individuals including their comorbidities, so is also a good predictor of SSI. ${ }^{2}$ SSI rates were significantly higher in patients with ASA II-V than in those with ASA I, which is in agreement with previous reports, ${ }^{35,36}$ suggesting that the ASA score before surgery has a strong influence on SSI rates in clean and clean contaminated cases.

According to the National Nosocomial Infection Surveillance SSI index (comprising ASA, potential for surgical wound contamination, and duration of surgery), ${ }^{37}$ the incidence of SSI was increased for scores $0,1,2$, and 3 (corresponding to $1.3 \%, 5.8 \%$, $5.1 \%$, and $30.0 \%$, respectively); although the rate in patients with a score of 1 was higher than in those with a score of 2 , this difference was not statistically significant, which is most likely due to the small size of the sample available for subanalysis. Based on our study and those reported by others, ${ }^{38,39}$ the incidence of SSI can be expected in those patients with high-risk factors.

Like other major inflammatory markers, the WBC is a stable, well standardized, widely available, and inexpensive biomarker of systemic inflammation..$^{40}$ Using multiple logistic regression, we found that an elevated procedural WBC level was an independent risk factor for development of SSI in patients undergoing a surgical procedure, which is in contrast with the findings of a previous study. ${ }^{41}$ These different results between hospitals may be related to different reference values being used in the laboratory and the number of patients involved. 
The main limitations of our study are related to our data set, lack of analysis of chlorhexidine bathing, normothermia, and other possible risk factors that may contribute to the low prevalence of SSI. In addition, less than 2 years of data (from July 2013 to December 2014) was considered in the analysis, and our results are not necessarily representative of other years. However, despite these limitations, our data suggest that six independent parameters are correlated with the risk of SSI and that relevant preventive measures should be implemented to reduce the incidence of SSI.

\section{Acknowledgments}

This work was supported by the Nature and Science Fund (project 81171433), National Institutes of Health (project 1D43TW007257-01A2), and Chinese Preventive Medicine Association Fund (project zhyy2013-11).

\section{Disclosure}

The authors report no conflicts of interest in this work.

\section{References}

1. Kim BD, Hsu WK, De Oliveira GS Jr, Saha S, Kim JY. Operative duration as an independent risk factor for postoperative complications in single-level lumbar fusion: an analysis of 4588 surgical cases. Spine (Phila Pa 1976). 2014;39:510-520.

2. Castro Pde T, Carvalho AL, Peres SV, Foschini MM, Passos AD. Surgical-site infection risk in oncologic digestive surgery. Braz J Infect Dis. 2011;15:109-115.

3. Awad SS. Adherence to surgical care improvement project measures and post-operative surgical site infections. Surg Infect (Larchmt). 2012; $13: 234-237$

4. Fiorio M, Marvaso A, Viganò F, Marchetti F. Incidence of surgical site infections in general surgery in Italy. Infection. 2006;34:310-314.

5. Ameh EA, Mshelbwala PM, Nasir AA, et al. Surgical site infection in children: prospective analysis of the burden and risk factors in a subSaharan African setting. Surg Infect (Larchmt). 2009;10:105-109.

6. Boltz MM, Hollenbeak CS, Julian KG, Ortenzi G, Dillon PW. Hospital costs associated with surgical site infections in general and vascular surgery patients. Surgery. 2011;150:934-942.

7. Mawalla B, Mshana SE, Chalya PL, Imirzalioglu C, Mahalu W. Predictors of surgical site infections among patients undergoing major surgery at Bugando Medical Centre in Northwestern Tanzania. BMC Surg. 2011;11:21.

8. Ministry of Health of the People's Republic of China. Diagnostic criteria for nosocomial infections (proposed). Natl Med J China. 2001;81: 314-320.

9. Burke JP. Infection control: a problem for patient safety. $N$ Engl J Med. 2003;348:651-656.

10. Liau KH, Aung KT, Chua N, et al. Outcome of a strategy to reduce surgical site infection in a tertiary-care hospital. Surg Infect (Larchmt). 2010; 11:151-159.

11. Anderson DJ. Surgical site infections. Infect Dis Clin North Am. 2011; $25: 135-153$

12. Maier S, Körner P, Diedrich S, Kramer A, Heidecke CD. [Definition and management of wound infections]. Chirurg. 2011;82:235-241. German.

13. Gaynes R, Richards C, Edwards J, et al. Feeding back surveillance data to prevent hospital-acquired infections. Emerg Infect Dis. 2001;7: 295-298.
14. Duque-Estrada EO, Duarte MR, Rodrigues DM, Raphael MD. Wound infections in pediatric surgery: a study of 575 patients in a university hospital. Pediatr Surg Int. 2003;19:436-438.

15. Devjani De, Saxena S, Mehta G, Yadav R, Dutta R. Risk factor analysis and microbial etiology of surgical site infections following lower segment caesarean section. International Journal of Antibiotics. 2013;2013: 283025.

16. Owens CD, Stoessel K. Surgical site infections: epidemiology, microbiology and prevention. $J$ Hosp Infect. 2008;70:3-10.

17. Lilienfeld DE, Vlahov D, Tenney JH, McLaughlin JS. Obesity and diabetes as risk factors for postoperative wound infections after cardiac surgery. Am J Infect Control. 1988;16:3-6.

18. Talbot TR. Diabetes mellitus and cardiothoracic surgical site infections. Am J Infect Control. 2005;33:353-359.

19. Pomposelli JJ, Baxter JK 3rd, Babineau TJ, et al. Early postoperative glucose control predicts nosocomial infection rate in diabetic patients. JPEN J Parenter Enteral Nutr. 1998;22:77-81.

20. Sessler DI. Nonpharmacologic prevention of surgical wound infection. Anesthesiol Clin. 2006;24:279-297.

21. Sanabria A, Vega V, Dominguez LC, Espitia E, Serna A, Osorio C. The evolution of laparoscopy in abdominal surgery: a meta-analysis of the effect on infectious outcomes. Minim Invasive Ther Allied Technol. 2014;23:74-86.

22. Motie MR, Ansari M, Nasrollahi HR. Assessment of surgical site infection risk factors at Imam Reza hospital, Mashhad, Iran between 2006 and 2011. Med J Islam Repub Iran. 2014;28:52.

23. Johnson A, Young D, Reilly J. Caesarean section surgical site infection surveillance. J Hosp Infect. 2006;64:30-35.

24. Chang CC, Lin HC, Lin HW, Lin HC. Anesthetic management and surgical site infections in total hip or knee replacement: a populationbased study. Anesthesiology. 2010;113:279-284.

25. Washington State Hospital Association. Washington State surgical site infection (SSI) event reporting. Available from: http://www.wsha.org/ files/82/SSIToolkit.pdf. Accessed July 15, 2015.

26. Richard PE. Surgical site infection prevention and control. An emerging paradigm. J Bone Joint Surg Am. 2009;91:2-9.

27. Walz JM, Paterson CA, Seligowski JM, Heard SO. Surgical site infection following bowel surgery: a retrospective analysis of 1446 patients. Arch Surg. 2006;141:1014-1018.

28. Jeong SJ, Ann HW, Kim JK, et al. Incidence and risk factors for surgical site infection after gastric surgery: a multicenter prospective cohort study. Infect Chemother. 2013;45:422-430.

29. Bucher BT, Guth RM, Elward AM, et al. Risk factors and outcomes of surgical site infection in children. J Am Coll Surg. 2011;212:1033-1038.

30. Traore O, Liotier J, Souweine B. Prospective study of arterial and central venous catheter colonization and of arterial-and central venous catheterrelated bacteremia in intensive care units. Crit Care Med. 2005;33: 1276-1280.

31. Walker J. Patient preparation for safe removal of surgical drains. Nurs Stand. 2007;21:39-41.

32. Leong G, Wilson J, Charlett A. Duration of operation as a risk factor for surgical site infection: comparison of English and US data. $J$ Hosp Infect. 2006;63:255-262.

33. Ercole FF, Starling CE, Chianca TC, Carneiro M. Applicability of the national nosocomial infections surveillance system risk index for the prediction of surgical site infections: a review. Braz J Infect Dis. 2007; 11:134-141

34. Raghavan M, Marik PE. Anemia, allogenic blood transfusion, and immunomodulation in the critically ill. Chest. 2005;127:295-307.

35. Khan M, Rooh-ul-Muqim, Zarin M, Khalil J, Salman M. Influence of ASA score and Charlson Comorbidity Index on the surgical site infection rates. J Coll Physicians Surg Pak. 2010;20:506-509.

36. Wloch C, Wilson J, Lamagni T, Harrington P, Charlett A, Sheridan E. Risk factors for surgical site infection following caesarean section in England: results from a multicentre cohort study. BJOG. 2012;119: 1324-1333. 
37. Ercole FF, Chianca TC, Duarte D, Starling CE, Carneiro M. Surgical site infection in patients submitted to orthopedic surgery: the NNIS risk index and risk prediction. Rev Lat Am Enfermagem. 2011;19:269-276.

38. Thu LT, Dibley MJ, Ewald B, Tien NP, Lam LD. Incidence of surgical site infections and accompanying risk factors in Vietnamese orthopaedic patients. J Hosp Infect. 2005;60:360-367.

39. Freitas PF, Campos ML, Cipriano ZM. [Suitability of the Hospital Infection National Surveillance System (NNISS) risk index for the prediction of the incidence of surgical site infection at a university hospital in Florianopolis, South Brazil]. Rev Assoc Med Bras. 2000;46(4):359-362. Portuguese.
40. Margolis KL, Manson JE, Greenland P, et al. Leukocyte count as a predictor of cardiovascular events and mortality in postmenopausal women: the Women's Health Initiative Observational Study. Arch Intern Med. 2005;165:500-508.

41. Greenblatt DY, Rajamanickam V, Mell MW. Predictors of surgical site infection after open lower extremity revascularization. J Vasc Surg. 2011; 54:433-439.

\section{Publish your work in this journal}

Patient Preference and Adherence is an international, peer-reviewed, open access journal that focuses on the growing importance of patient preference and adherence throughout the therapeutic continuum. Patient satisfaction, acceptability, quality of life, compliance, persistence and their role in developing new therapeutic modalities and compounds to optimize clinical outcomes for existing disease states are major areas of interest for the journal. This journal has been accepted for indexing on PubMed Central. The manuscript management system is completely online and includes a very quick and fair peer-review system, which is all easy to use. Visit http://www. dovepress.com/testimonials.php to read real quotes from published authors.

Submit your manuscript here: http://www.dovepress.com/patient-preference-and-adherence-journal 